\title{
Preliminary Blood Compatibility Comparison of Silk Fibroin Dissolved by different Solvents
}

\author{
Ling zhang1, Mengyao Ding1, Guangzhou Song1, Wei Tian¹, Helei Li ${ }^{1}$, Honggen Yi $^{1}$, Yin Yin ${ }^{2}$, Fenglin Dong ${ }^{3}$ and \\ Jiannan Wang ${ }^{1 *}$
}

${ }^{1}$ National Engineering Laboratory for Modern, China

${ }^{2}$ Laboratory Animal Research Centre, China

${ }^{3}$ Department of Ultrasonography, China

Received: 制: November 29, 2018; Published: 講: December 17, 2018

*Corresponding author: Jiannan Wang and Ling zhang National Engineering Laboratory for Modern Silk, College of Textile and Clothing Engineering, Suzhou Industrial Park, Suzhou, Jiangsu Province, 215123, China

\begin{abstract}
Silk fibroin possesses good cytocompatibility and biodegradability, was a potential material for wound haemostasis. $\mathrm{Ca}^{2+}$ acts as a coagulation factor in cascade pathway for thrombin generation, it can be chelated to silk fibroin molecule. We used three neutral salt solvents $\left(\mathrm{CaCl}{ }_{2}, \mathrm{Ca}\left(\mathrm{NO}_{3}\right)_{2}\right.$ and $\mathrm{LiBr}$ ) to dissolve silk fibers and prepare regenerated silk fibroin materials, preliminarily explored blood compatibility. Results showed that the regenerated silk fibroin materials prepared by calcium salt dissolving could shorten thrombin time and plasma recalcification time, compared with non-calcium salt reagent $\mathrm{LiBr}$.
\end{abstract}

Keywords: Silk Fibroin; Calcium Salt; Lithium Salt; Hemolysis; Blood Coagulation

\section{Introduction}

Haemorrhage still remains a leading cause of early death and infectious complications in trauma or combat wounds continue to challenge caregivers. Various materials (such as gelatine, fibrin glue, chitosan, collagen, and inorganic microporous materials) have been developed as haemostatic materials [1-5]. On market currently, gelatine and chitosan have attracted several clinically proven products for wound haemostasis. Collagen is also considered a promising biomaterial for wound haemostasis [1,5], but it does not have the ability to induce the rapid hemostasis required for surgical applications [6,7]. Chitosan, as a haemostatic material, is able to stop low pressure arterial bleeds, but is flimsy to maintain hemostasis after intravenous administration of fluids, leading to the risk of rebleeding [8]. After modification, the haemostatic efficiency of chitosan can be improved $[9,10]$. Collagen, gelatine and chitosan do not have physiological haemostatic functions.

In the coagulation mechanism, $\mathrm{Ca}^{2+}$ is indispensable in cascade pathway for thrombin generation. On a wound, $\mathrm{Ca}^{2+}$ interacts with platelet surface phospholipids to activate thrombin, and then digest fibrinogen into fibrin, resulting in coagulation formation. So, calcium alginate has been paid more attention to the applications in embolization [11-13]. However, the cytocompatibility of calcium alginate is not satisfactory. Therefore, it is desired to develop a haemostatic materials with comprehensive ability, combining physical properties, good cytocompatibility and physiologically haemostatic properties. Silk fibroin is a natural animal protein, rich in sources, however, the developments on the haemostatic function of SF materials are lacking. Silk fibroin possesses good cytocompatibility and biodegradability, has been proved for cells adhere and proliferate [14-16], also has been considered as potential tissue engineering scaffolds and drug delivery carriers [16-21]. Interestingly, silk fibroin has a large number of functional groups, such as $-\mathrm{COOH}$ of glutamic acid or aspartic acid, $-\mathrm{NH}_{2}$ of lysine and $-\mathrm{OH}$ of serine or Tyrosine [22-24], which can interact with $\mathrm{Ca}^{2+}$ by electrostatic interaction and coordination bonds. In the study, we prepared silk fibroin porous haemostatic materials by different solvents, and investigated Hemolysis and clotting capability, expecting to expand the application of silk fibroin in haemostatic materials. 


\section{Materials and Methods \\ Preparation of Silk Fibroin Solution}

Raw silk was treated with boiling $\mathrm{Na}_{2} \mathrm{CO}_{3}$ solution to remove sericin, as described previously [16]. After drying, degummed silk fibre was dissolved in a ternary solvent $\mathrm{CaCl}_{2} \cdot \mathrm{CH}_{3} \mathrm{CH}_{2} \mathrm{OH} \cdot \mathrm{H}_{2} \mathrm{O}$ (mole ratio, $1: 2: 8$ ) at $70{ }^{\circ} \mathrm{C}$ or $9.3 \mathrm{M}$ of $\mathrm{LiBr}$ at $60^{\circ} \mathrm{C}$ or molten $\mathrm{Ca}\left(\mathrm{NO}_{3}\right)_{2}$ at $85^{\circ} \mathrm{C}$ and stirred until completely dissolved. After dialyzing against deionized water, concentrating and filtering the mixed solution to obtain silk fibroin aqueous solution $(6 \%, w: w)$.

\section{Preparation of Silk Fibroin Materials}

$6 \%$ of silk fibroin aqueous solution were mixed with polyethylene glycol diglycidyl ether (Sigma, USA) at a weight ratio of 1.0: $0.8(\mathrm{w} / \mathrm{w})$ and stirred to ensure entirely mixing. The mixture was cast into 6-well cell culture plate, then prefrozen at $-80{ }^{\circ} \mathrm{C}$ for $8 \mathrm{~h}$ and freeze-dried for $24 \mathrm{~h}$ to prepare porous materials. After impregnation in deionized water at $4{ }^{\circ} \mathrm{C}$ for $72 \mathrm{~h}$ to remove unreacted residues, porous materials were freeze-dried again. Regenerated silk fibroin materials were named to $\mathrm{SF}-\mathrm{CaCl}_{2}, \mathrm{SF}-\mathrm{LiBr}$, $\mathrm{SF}-\mathrm{Ca}\left(\mathrm{NO}_{3}\right)_{2}$, respectively. Commercial calcium alginate porous material was used as a control.

\section{Hemolysis Assay}

Specimens were equilibrated in saline $(0.9 \%, \mathrm{w}: \mathrm{v} ; \mathrm{NaCl})$ at $37^{\circ} \mathrm{C}$ for $30 \mathrm{~min}$. Whole blood from a healthy rabbit $(2.5 \mathrm{~kg}$, New Zealand; the Laboratory Animal Research Centre, Soochow University, China) was collected into sterile sodium citrate buffer [25], then the specimens were soaked in diluted rabbit blood $(0.2 \mathrm{ml}$ in $10 \mathrm{ml}$ saline) to incubate at $37{ }^{\circ} \mathrm{C}$ for $60 \mathrm{~min}$. Distilled water and physiological saline were used as positive and negative controls, respectively. After centrifuging at $2500 \mathrm{rpm}$ for $5 \mathrm{~min}$, the absorbance of the supernatant was recorded at $545 \mathrm{~nm}$ using a Synergy HT microplate reader (BIO-TEK, USA). The Hemolysis percentage was calculated according to the following equation, where $A_{1}, A_{2}$, and $A_{3}$ are the absorbance of the negative control, sample, and positive control, respectively. All samples were analysed in triplicate.

$$
\text { Hemolysis rate }(\%)=\frac{A_{2}-A_{1}}{A_{3}-A_{1}} \times 100 \%
$$

\section{Coagulation Time Testing}

Fresh blood from a rabbit (2.5kg, New Zealand) was collected and mixed with sterile sodium citrate. Specimens were placed in mixture solution and incubated at $37{ }^{\circ} \mathrm{C}$ for $30 \mathrm{~min}$. After removing samples, the Platelet-Poor Plasma (PPP) supernatant was collected by centrifuging at $3000 \mathrm{rpm}$ for $5 \mathrm{~min}$. Activated Partial Thrombin Time (APTT), Prothrombin Time (PT) and Thrombin Time (TT) were determined according to the instructions supplied with the relevant kits (Nanjing Jian cheng Bioengineering Institute, China). Briefly, APTT assay, $50 \mu \mathrm{L}$ PPP supernatant was mixed with $50 \mu \mathrm{L}$ APTT reagent and incubated at $37{ }^{\circ} \mathrm{C}$ for $3 \mathrm{~min}$, followed by the addition of $50 \mu \mathrm{L}$ preheated $\mathrm{CaCl}_{2}(0.03 \mathrm{~mol} / \mathrm{L})$ and mixing; PT assay, $50 \mu \mathrm{L}$ PPP supernatant was incubated at $37^{\circ} \mathrm{C}$ for $3 \mathrm{~min}$, then mixed with $100 \mu \mathrm{L}$ preheated PT reagent; TT assay, $100 \mu \mathrm{L}$ PPP supernatant was incubated at $37^{\circ} \mathrm{C}$ for $3 \mathrm{~min}$ and mixed with $100 \mu \mathrm{L}$ TT reagent.
After the addition of the activators in the above procedures, the time taken for the first clotting to appear was recorded instantly. All samples were analysed in quintuplicate.

\section{Plasma Recalcification Time (PRT) Testing}

Whole blood in sodium citrate buffer was centrifuged at $1500 \mathrm{rpm}$ for $15 \mathrm{~min}$ to obtain Platelet-Rich Plasma (PRP) supernatant. Specimens were pre-equilibrated with saline for $24 \mathrm{~h}$ and further incubated with PRP at $37^{\circ} \mathrm{C}$ for $3 \mathrm{~min}$, then added $0.025 \mathrm{M} \mathrm{CaCl}_{2}$ to accelerate recalcification at $37^{\circ} \mathrm{C}$. PRP supernatant without materials was used as control group. The time taken for fibrin clots to appear was recorded as the PRT. All samples were analysed in triplicate.

\section{Statistics}

Data are presented as mean \pm standard deviation of the mean. Comparisons of means were performed using one-way Analysis of Variance (ANOVA), followed by the independent sample t-test using SPSS 17.0 statistical software. A p-value lower than 0.05 was considered as statistically significant.

\section{Results and Discussion}

\section{Hemolysis of Silk Fibroin}

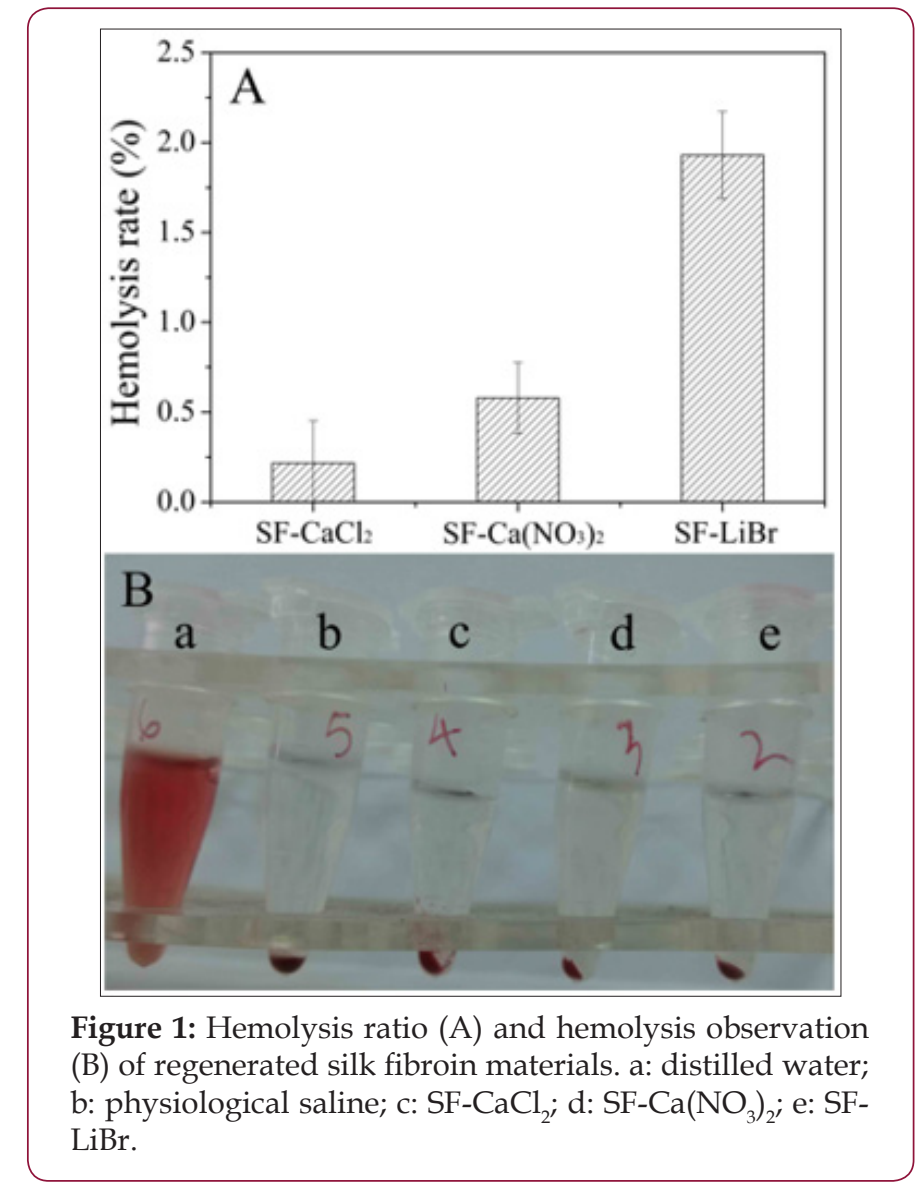

Lithium salt (such as LiBr and LiSCN) and calcium salt (such as $\mathrm{CaCl}_{2}$ and $\mathrm{Ca}\left(\mathrm{NO}_{3}\right)_{2}$ ) are recognized solvents used to prepare regenerated silk fibroin materials $[16,26,27]$. In this work, we used $\mathrm{LiBr}, \mathrm{CaCl}_{2}$ and $\mathrm{Ca}\left(\mathrm{NO}_{3}\right)_{2}$ to dissolve silk fibers. Figure 1 showed the 
haemolytic properties of regenerated silk fibroin porous materials. The Hemolysis ratios of regenerated silk fibroin materials prepared by different dissolution methods were all less than 2\% (Figure 1A) and were therefore non-hemolytic [28]. All samples did not damage the red blood cells any more than did the negative control (physiological saline) (Figure 1B). In contrast, the positive control (distilled water) caused extensive damage to the red blood cells, which released large quantities of haemoglobin as a result.

\section{Coagulation Time Analysis of Silk Fibroin}

Coagulation system is complex involving various factors that act on both intrinsic and extrinsic activation pathways. Herein, APTT, PT and TT were investigated to evaluate clotting capability of regenerated silk fibroin porous materials dissolved by different solvents (Figure 2). The PT value of SF- $\mathrm{CaCl}_{2}$ and $\mathrm{SF}-\mathrm{Ca}\left(\mathrm{NO}_{3}\right)_{2}$ were shorter than that of SF- $\mathrm{LiBr}$, similar to calcium alginate (Figure 2A). Thromboplastin is the key factor in blood coagulation, in the PT test, there was no obvious difference in the results between samples due to the addition of sufficient thromboplastin and appropriate $\mathrm{Ca}^{2+}$. The APTT reflected the clotting ability depending on $\mathrm{Ca}^{2+}$ activating. Although silk fibroin dissolved with calcium salt contained a small amount of chelated $\mathrm{Ca}^{2+}$ and a little $\mathrm{CaCl}_{2}$ reagent were added, it is far less than that of calcium alginate. Therefore, the APTT values of silk fibroin materials were much longer than that of calcium alginate (Figure 2B). In the TT test by adding prothrombin without $\mathrm{Ca}^{2+}$, the TT values for silk fibroin materials dissolved by calcium salt were significantly shorter than that by $\mathrm{LiBr}$, while slightly longer than that of calcium alginate (Figure 2C). In this test, $\mathrm{Ca}^{2+}$ is also indispensable and played a significant role to activate platelets to release thrombin activating factor, thereby converting prothrombin into thrombin. This $\mathrm{Ca}^{2+}$ was only derived from plasma or materials, so the TT values of SF-CaCl ${ }_{2}$ and $\mathrm{SF}-\mathrm{Ca}\left(\mathrm{NO}_{3}\right)_{2}$ were shorter than that of SF-LiBr with significant differences, although there was only a small amounts of chelated $\mathrm{Ca}^{2+}$ in calcium salt dissolved silk fibroin materials.

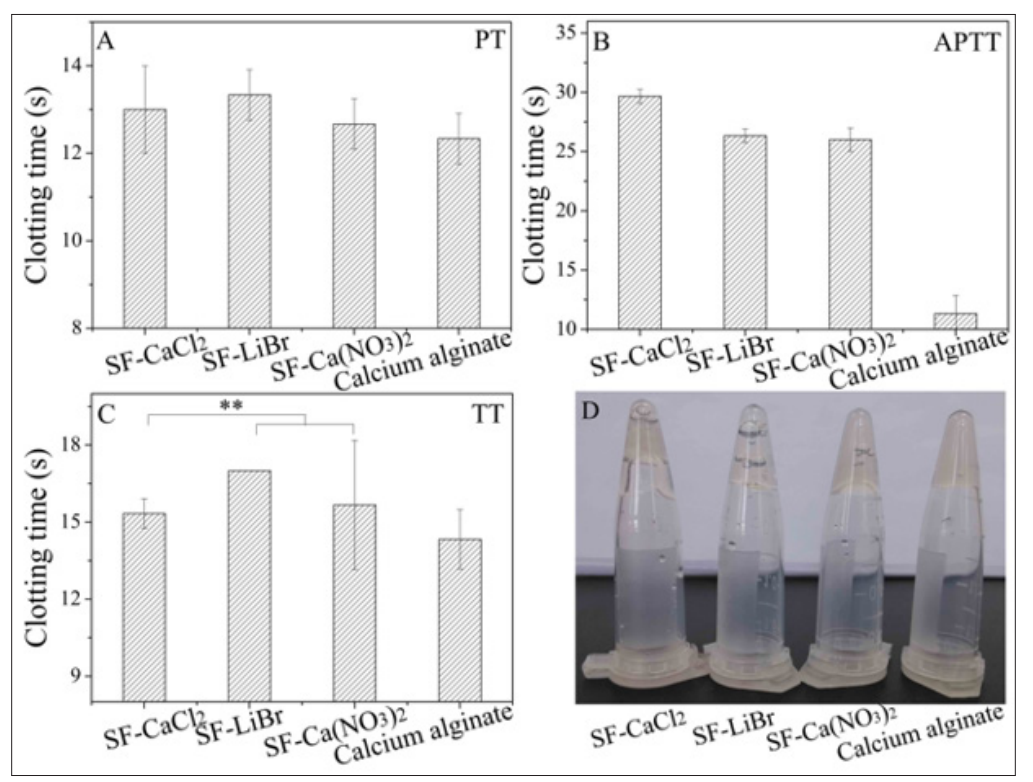

Figure 2: Clotting capability (A-C) and clotting observation (D) of regenerated silk fibroin materials. ${ }^{* *} \mathrm{p}<0.01$.

\section{Recalcification of Silk Fibroin}

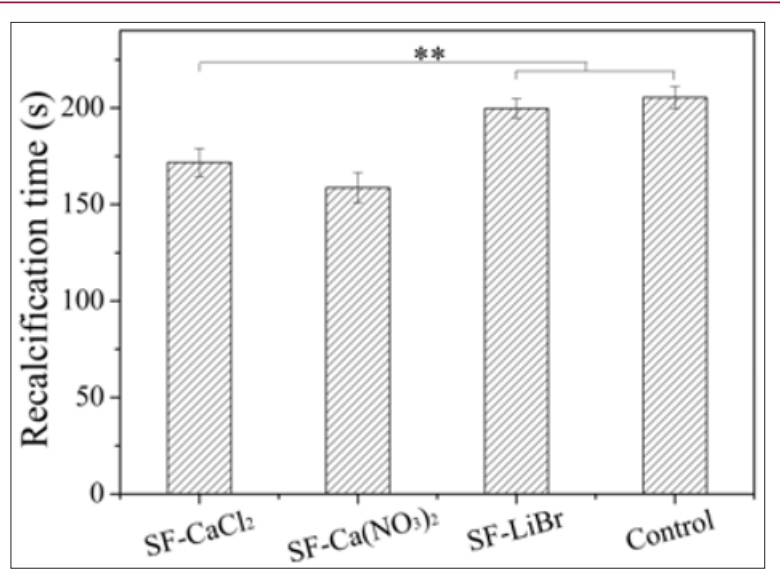

Figure 3: Recalcification time of regenerated silk fibroin materials ${ }^{* *} \mathrm{p}<0.01$.
Plasma recalcification time is a convenient measure of the endogenous anticoagulation properties of biomaterials. The recalcification time of regenerated silk fibroin materials dissolved with $\mathrm{CaCl}_{2}$ and $\mathrm{Ca}\left(\mathrm{NO}_{3}\right)_{2}$ was significantly shorter than that with $\mathrm{LiBr}$ (Figure 3) and that of control. The results also because of remained bivalent $\mathrm{Ca}^{2+}$, which chelated with $-\mathrm{NH}_{2}$ or $-\mathrm{OH}$ of silk fibroin, activated rich platelets to release thrombin activating factor and promote fibrin formation, resulting in shorter recalcification time of regenerated silk fibroin prepared by calcium salt dissolving.

\section{Conclusion}

Silk fibroin molecules can chelate with $\mathrm{Ca}^{2+}$, a small amount of chelated $\mathrm{Ca}^{2+}$ remained in the silk fibroin materials by calcium salt dissolving and dialyzing. Results showed that the regenerated silk fibroin materials prepared with calcium salt dissolution had a prominent advantage for shortening clotting time compared with non-calcium salt reagent. The study provided an idea to develop silk 
fibroin haemostatic materials by using a more suitable preparation method, such as regulating the $\mathrm{Ca}^{2+}$ concentration.

\section{Acknowledgement}

This work was supported by National Natural Science Foundation of China [Nos 51473108, 51873141], Natural Science Foundation of Jiangsu Province of China [No BK20181192] and College Natural Science Research Project of Jiangsu Province of China [No 18KJA540001].s

\section{References}

1. Alpaslan C, Alpaslan GH, Oygur T (1997) Tissue reaction to three subcutaneously implanted local hemostatic agents. Br J Oral Maxillofac Surg 35(2): 129-132.

2. Carraway JW, Kent D, Young K, Cole A, Friedman R, et al. (2008) Comparison of a new mineral based hemostatic agent to a commercially available granular zeolite agent for hemostasis in a swine model of lethal extremity arterial hemorrhage. Resuscitation 78(2): 230-235.

3. Sambasivan CN, Cho SD, Zink KA, Differding JA, Schreiber MA, et al. (2009) A highly porous silica and chitosan-based hemostatic dressing is superior in controlling hemorrhage in a severe groin injury model in swine. Am J Surg 197(5): 576-580.

4. Al Qahtani K (2011) Initial experience with hemostatic fibrin glue as adjuvant during drainless parotidectomy. Saudi Dent J 23(2): 67-71.

5. Manon Jensen T, Kjeld NG, Karsdal MA, Thromb J (2016) Collagenmediated hemostasis. J Thromb Haemost 14(3): 438-448.

6. Gazzeri R, Galarza M, Fiore C, Callovini G, Alfieri A (2015) Use of tissueglue-coated collagen sponge (Tachosil) to repair minor cerebral dural venous sinus lacerations: technical note. Neurosurgery 11 Suppl 2: 3236.

7. Wong C, Liu Y, Yip J, Chand R, Wee JL, et al. (2009) CEACAM1 negatively regulates platelet-collagen interactions and thrombus growth in vitro and in vivo. Blood 113(8): 1818-1828.

8. Kheirabadi BS, Scherer MR, Estep JS, Dubick MA, Holcomb JB (2009) Determination of efficacy of new hemostatic dressings in a model of extremity arterial hemorrhage in swine. J Trauma 67(3): 450-460.

9. Bochicchio G, Kilbourne M, Kuehn R, Keledjian K, Hess J, et al. (2009) Use of a modified chitosan dressing in a hypothermic coagulopathic grade $V$ liver injury model. Am J Surg 198(5): 617-622.

10. Chan LW, Kim CH, Wang X, Pun SH, White NJ, et al. (2016) PolySTATmodified chitosan gauzes for improved hemostasis in external hemorrhage. Acta Biomater 31: 178-185.

11. Jarvis PM, Galvin DAJ, Blair SD, Mccollum CN (1987) How does calcium alginate achieve haemostasis in surgery? J Thromb Haemost 58(01): 080.

12. Xu GZ, Cheng L, Zhang QT, Sun YL, Chen CL, et al. (2016) In situ thiolated alginate hydrogel: Instant formation and its application in hemostasis. J Biomater Appl 31(5): 721-729.

ISSN: 2574-1241

DOI: 10.26717/BJSTR.2018.12.002233

Jiannan Wang. Biomed J Sci \& Tech Res

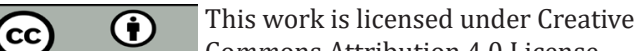

This work is licensed under Creative

Submission Link: https://biomedres.us/submit-manuscript.php
13. Forster REJ, Thurmer F, Wallrapp C, Lloyd AW, Macfarlane W, et al. (2010) Characterisation of physico-mechanical properties and degradation potential of calcium alginate beads for use in embolization. J Mater Sci Mater Med 21(7): 2243-2251.

14. Sun XL, Hao YX, Wang QY, Dong FL, Wang JN (2016) Cell growth and proliferation on the interface of a silk fabric tubular scaffold. Textile Res J 86: 2193-2201.

15. Tu FF, Liu YF, Li HL, Shi PG, Hao YX, et al. (2018) Vascular cell co-culture on silk fibroin matrix. Polymers 10(1): 39.

16. Wang JN, Wei YL, Yi HG, Liu ZW, Sun D, et al. (2014) Cytocompatibility of a silk fibroin tubular scaffold. Mater Sci Eng C Mater Biol Appl 34: 429-436.

17. Wei YL, Sun D, Yi HG, Wang JN (2014) Characterization of a PEG-DE cross-linked tubular silk scaffold. Textile Res J 84(9): 959-967.

18. Liu YF, Tu FF, Li HL, Shi PG, Yin Y, etal. (2018) Preparation, characterization and in vivo graft patency of a silk fibroin tubular scaffold. Mater Technol 33: 227-234.

19. Farokhi M, Mottaghitalab F, Samani S, Shokrgozar MA, Kundu SC, et al. (2018) Preparation of a codelivery system based on vancomycin/silk scaffold containing silk nanoparticle loaded VEGF. ACS Biomater Sci \& Eng 4(8): 2836-2846.

20. Chouhan D, Lohe T, Samudrala PK, Mandal BB (2018) In situ forming injectable silk fibroin hydrogel promotes skin regeneration in full thickness burn wounds. Adv Healthcare Mater, pp. e1801092.

21. Sheikh FA, Ju HW, Lee JM, Moon BM, Park HJ, et al. (2015) 3D electrospun silk fibroin nanofibers for fabrication of artificial skin. Nanomedicine 11(3): 681-691.

22. Wang JN, Yan SQ Lu CD, Bai L (2009) Biosynthesis and characterization of typical fibroin crystalline polypeptides of silkworm Bombyx mori. Mater Sci Eng 29(4): 1321-1325.

23. Yang GQ, Wu MY, Yi HG, Wang JN (2016) Biosynthesis and characterization of a non-repetitive polypeptide derived from silk fibroin heavy chain. Mater Sci Eng C Mater Biol Appl 59: 278-285.

24. Wu Y, Kang Z, Tian ZF, Wu MY, Wang JN (2017) Biosynthesis and characterization of recombinant silk-like polypeptides derived from the heavy chain of silk fibroin. Polymers 9(12): 669.

25. Sun D, Hao YX, Yang GQ Wang JN (2015) Hemocompatibility and cytocompatibility of the hirudin-modified silk fibroin. J Biomed Mater Res B Appl Biomater 103(3): 556-562.

26. Ko E, Lee JS, Kim H, Yang SY, Yang D, et al. (2018) Electrospun silk fibroin nanofibrous scaffolds with two-stage hydroxyapatite functionalization for enhancing the osteogenic differentiation of human adipose-derived mesenchymal stem cells. ACS Appl Mater Interfaces 10(9): 7614-7625.

27. Mathur AB, Tonelli A, Rathke T, Hudson S (2010) The dissolution and characterization of Bombyx mori silk fibroin in calcium nitrate-methanol solution and the regeneration of films. Biopolymers 42(1): 61-74.

28. (2003) ASTM Medical Devices, Emergency Medical Services: ASTM International 13: 309.

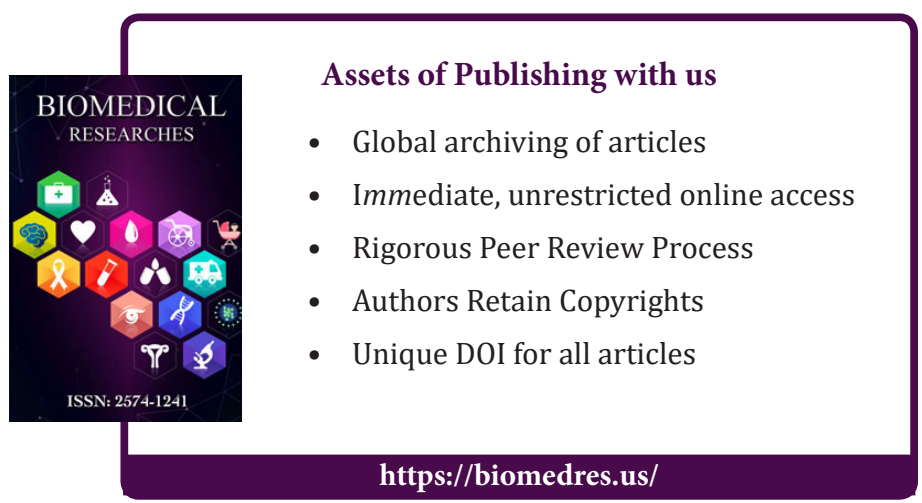

Cite this article: Ling z, Mengyao D, Guangzhou S, Wei T, Jiannan W, et al., Preliminary Blood Compatibility Comparison of Silk Fibroin Dissolved by different Solvents. Biomed J Sci \& Tech Res 12(2)-2018. BJSTR. MS.ID.002233. DOI: 10.26717/ BJSTR.2018.12.002233. 